\title{
Pendugaan laju sedimentasi pada kolam tanah budidaya ikan patin intensif di Desa Koto Mesjid Kecamatan XIII Koto Kampar
}

\section{Saberina Hasibuan ${ }^{* 1}$, Syafriadiman ${ }^{\mathbb{1}}$, Atria Martina ${ }^{2}$, Henni Syawal ${ }^{1}$, \& Rinaldi ${ }^{3}$}

${ }^{1} J u r u s a n$ Budidaya Perairan, Fakultas Perikanan dan Kelautan, Universitas Riau

2Jurusan Biologi, Fakultas Matematika dan IImu Pengetahuan Alam, Universitas Riau

${ }^{3}$ Jurusan Teknik Sipil, Fakultas Teknik, Universitas Riau

*saberina.hasibuan@lecturer.unri.ac.id

\begin{abstract}
The potential of fisheries in Koto Mesjid Village XIII Koto Kampar districts has had a tremendous impact on people's income. The total area of the Patin pond in Koto Mesjid village has reached 62 hectares. The production reaches six tons per day. Training in prediction the rate of sedimentation in intensive catfish aquaculture ponds in the village of Koto Mesjid has resulted in a way to monitor the quality of pond water through the measurement of suspended solids using a solid trap device. The average suspended solids at all pond ages are $19.5 \mathrm{ml} / \mathrm{L}$ per day and $129.25 \mathrm{ml} / \mathrm{L}$ per week. Based on this data, the management of the pond bottom must be carried out every harvest, mainly when drying the pond needs to drain mud. Patin fish farmers have very high enthusiasm to practice the tools in their respective ponds. The existence of this counseling is very useful in providing knowledge so that people who work as Patin fish farmers can manage the time to replace pond water easily.
\end{abstract}

\begin{abstract}
Abstrak Potensi perikanan di Koto Mesjid Kecamatan XIII Koto Kampar telah memberikan dampak yang luar biasa bagi pendapatan masyarakat. Total luas kolam Patin di Koto Mesjid telah mencapai 62 hektar. Hasil produksi mencapai enam ton perhari. Pelatihan pendugaan laju sedimentasi pada kolam tanah budidaya ikan patin intensif di desa Koto Mesjid telah menghasilkan cara pemantauan kualitas air kolam melalui pengukuran padatan tersuspensi menggunakan alat perangkap padatan. Rata-rata padatan tersuspensi pada semua umur kolam adalah 19,5 ml/L perhari dan $129,25 \mathrm{ml} / \mathrm{L}$ per minggu. Berdasarkan data ini maka pengelolaan dasar kolam harus dilakukan setiap panen terutama saat pengeringan kolam perlu pengurasan lumpur. Petani ikan Patin memiliki antusias sangat tinggi untuk mempraktekkan alat pada kolam masing-masing. Adanya penyuluhan ini sangat bermanfaat dalam memberikan bekal ilmu pengetahuan sehingga masyarakat yang berprofesi sebagai petani ikan Patin dapat mengatur waktu penggantian air kolam dengan mudah.
\end{abstract}

Keywords: traces of sediment; suspended solids; sedimentation rate; mud; intensive

\section{OOPEN ACCESS \\ Citation: Hasibuan, S., Syafriadiman, A. Martina, H. Syawal, \& Rinaldi. 2019. Pendugaan laju sedimentasi pada kolam tanah budidaya ikan patin intensif di Desa Koto Mesjid Kecamatan XIII Koto Kampar. Riau Journal of Empowerment 2(2): 71-80 https://doi.org/10.31258/raje.2.2.71-80}

Paper type: Community service

Received: 2019-04-22 Revised: 2019-09-19 Accepted: 2019-09-23

Language: Bahasa Indonesia (id)

Funding: Lembaga Penelitian dan Pengabdian kepada Masyarakat Universitas Riau skema hibah Pengabdian kepada Masyarakat tahun anggaran 2018 dengan nomor kontrak 1292/UN.19.5.1.3/PP/2018

ISSN 2623-1549 (online), 2654-4520 (print)

(c) 2019 Saberina Hasibuan et al. The article by Author(s) is licensed under a Creative Commons Attribution 4.0 International License. This license permits unrestricted use, distribution, and reproduction in any medium, provided the original author and source are credited. 


\section{PENDAHULUAN}

Desa Koto Mesjid awalnya merupakan kawasan hamparan luas perbukitan dengan kontur lembah yang mengalir anak-anak sungai dan sekarang menjadi PLTA Koto Panjang. Pada tahun 1992, ada lima desa di kawasan ini yang ditenggelamkan untuk membangun waduk PLTA. Akhirnya, masyarakat pindah menuju desanya yang sekarang yaitu Desa Koto Mesjid dengan aktifitas yang sama yaitu budidaya ikan.

Potensi perikanan di Koto Mesjid memang memberikan dampak yang luar biasa bagi kemajuan desa ini. Total luas kolam patin di Koto Mesjid saat ini telah mencapai 62 hektar. Jumlah ini akan terus bertambah karena minat warga yang luar biaya dalam budidaya ikan Patin. Hasil produksi ikan Patin ini telah mencapai Enam ton perhari. Putaran uang di Kampung Patin ini mencapai Rp 90 juta perhari. Potensi besar di bidang perikanan telah mampu membuat masyarakat Desa Koto Mesjid bebas dari ancaman pengangguran. Seluruh masyarakat desa Koto Mesjid hamper semuanya yang berprofesi sebagai pelaku budidaya perikanan. Hal ini jelas memberikan dampak ekonomi yang luar biasa bagi Kampung Patin. Keberhasilan dalam memproduksi ikan segar, juga diikuti dengan keberhasilan memproduksi berbagai olahan dari ikan Patin, seperti ikan Asap atau Salai, Nugget ikan, Bakso ikan dan Abon ikan. Bahkan, desa ini telah mempunyai sentra pengolahan ikan sendiri. Pada sentra ini terdapat lebih dari 50 tempat penyalaian dan setiap hari sentra ini membutuhkan 3 ton ikan sebagai bahan baku, sehingga sentra ini mampu memproduksi sekitar 3 ton ikan Salai perminggu atau 12 ton ikan Salai bisa dihasilkan perbulannya.

Kegiatan budidaya ikan Patin di desa Koto Mesjid tergolong intensif. Padat tebar ikan telah mencapai 50 ekor per meter ${ }^{2}$, penggunaan pakan pelet hasil formulasi sendiri dan dibuat menggunakan bahan-bahan yang tergolong murah seperti ikan asin untuk dijadikan tepung ikan, dan dedak. Pemberian pakan dalam jumlah besar berpotensi meningkatkan padatan tersuspensi pada kolom air dan akhirnya menumpuk di dasar kolam. Laju sedimentasi pakan pada kolam tanah yang tergolong Podsolik Merah Kuning (PMK) perlu diketahui agar kegiatan budidaya dapat dilakukan secara berkesinbungan.

Kegiatan pengabdian kepada masyarakat yang dilakukan Tim terhadap 25 orang kelompok pelaku budidaya ikan Patin secara intensif berupa praktek pengukuran padatan tersuspensi yang dijadikan sebagai dasar penetuan laju sedimentasi pada kolam tanah PMK budidaya ikan Patin Intensif di Desa Koto Mesjid Kecamatan XIII Koto Kampar. Pengabdian ini bertujuan untuk menambah pengetahuan dan keterampilan pelaku budidaya serta mengajarkan teknik pengukuran padatan tersuspensi pada alat perangkap yang dinyatakan dalam satuan $\mathrm{ml} / \mathrm{L}$. Setelah kegiatan praktek ini diharapkan seluruh peserta kelompok pelaku budidaya mampu menguasai dan menerapkannya dalam upaya pengelolaan kolam, sehingga produktivitas kolam dapat ditingkatkan.

Tanah dasar kolam (TDK) merupakan faktor yang sangat penting (utama) dalam budidaya ikan, karena mutu bahan dasar TDK sangat berpengaruh terhadap kualitas air kolam di atasnya dan pada gilirannya akan berpengaruh kuat terhadap kehidupan (produksi) ikan yang dibudidayakan di dalam kolam tersebut (Hasibuan, 2011, 2012; Hasibuan et al., 2011). Sonnenholzner dan Boyd (2000) mengatakan bahwa kolam yang berpotensi untuk menghasilkan ikan yang baik dipengaruhi oleh $\mathrm{pH}$ dan bahan organik, nitrogen dan fosfor di dalam tanah.

Ilustrasi profil TDK sebagai berikut: 1) Lapisan penjonjotan $=\mathrm{F}$ (flocculent layer) $1-<2$ $\mathrm{cm}, 2$ ) Lapisan campuran TDK $=\mathrm{S}$ (mixed sediment layer) $2-5 \mathrm{~cm}, 3$ ) Lapisan TDK matang dan mantap $=M$ (matures stable sediment) $5-15 \mathrm{~cm}$, dan 4) Lapisan peralihan $=\mathrm{T}$ (transitional layer) $15-20 \mathrm{~cm}, 5)$ Lapisan dasar kolam asli dan tidak terusik ( $\mathrm{P}=$ parent layer/original undisturbed pond bottom $)>20 \mathrm{~cm}$ mencerminkan kondisi tanah asli lokasi kolam berada. Lapisan F dan S berperan sangat penting dalam budidaya ikan, karena pada daerah ini terjadi proses pertukaran hara yang pada gilirannya akan berpengaruh terhadap kualitas air (Sonnenholzner \& Boyd, 2000). 
Lapisan F bersifat oksidatif dan S hanya beberapa milimeter di bawah permukaan tanah. Pada lapisan ini akan terjadi penumpukan lumpur apabila padatan tersuspensi cukup tinggi di kolom air. Oksigen terlarut tidak dapat terdifusi secara cepat ke TDK karena harus melalui ruang pori tanah yang terisi air. Kebutuhan mikroorganisme terhadap oksigen terlarut yang meningkat dapat berakibat pada terbentuknya kondisi anaerobik. Jika pada lapisan aerobik permukaan tanah memiliki warna lebih terang maka pada lapisan anaerobik ini tanah berwarna abu-abu atau hitam, sebagai akibat hadirnya besi ferro. Untuk meningkatkan produksi kolam maka pengelolaan TDK yang harus dilakukan adalah pengurasan sedimen/lumpur pada lapisan $\mathrm{F}$ dan $\mathrm{S}$ setelah panen ikan.

Pada TDK, jumlah dan jenis fraksi lempung dan bahan organik memegang peranan penting dalam menentukan berat volume tanah. Proses pembentukan lapisan TDK dipengaruhi oleh berat volume tanah. Semakin bertambah jeluk, berat volume TDK mendekati konstan sekitar $1,5 \mathrm{~g} / \mathrm{cm}^{3}$, sedangkan kadar C-organik makin besar mendekati permukaan TDK (Sonnenholzner \& Boyd, 2000). Tekstur tanah memegang peranan yang sangat penting dalam menentukan kesesuaian tanah sebagai tanah dasar kolam. Kandungan bahan organik dan mineral yang terdapat di dalam tanah dasar kolam penting untuk diketahui agar kesuburan tanah dapat terkelola dengan baik (Hasibuan, 2012). Kadar dan intensitas mineral sekunder pada TDK meningkat berbanding lurus dengan penambahan kadar lempung (clay) yang terdapat pada fraksi tanah. Peningkatan kadar lempung dan bahan organik pada TDK berbanding terbalik dengan nilai BV (Hasibuan et al., 2011).

\section{METODE PENERAPAN}

Kegiatan penyuluhan ini didasari oleh pengukuran pengetahuan para pelaku budidaya tentang laju sedimentasi di kolam. Kemampuan dalam bidang pengetahuan ini diukur dengan menyebarkan kuisioner yang sama kepada peserta penyuluhan dan diberikan dua tahap yaitu sebelum disampaikan materi penyuluhan (awal) dan sesudah selesai melakukan praktek perangkaian alat sedimen trap (akhir). Tujuan kegiatan ini adalah untuk mengetahui kemampuan para peserta pelaku usaha budidaya tentang laju sedimentasi di kolam.

Metoda penerapan kegiatan pengabdian pada masyarakat ini dilakukan dengan cara:

\section{Penyampaian materi penyuluhan dengan ceramah}

Materi penyuluhan yang disampaikan tentang Teknik Laju Sedimentasi pada Kolam Tanah PMK Budidaya Ikan Patin Intensif di Desa Koto Mesjid Kecamatan XIII Koto Kampar. Kegiatan penyampaian materi ini diberikan kepada kelompok pelaku budidaya ikan Patin Agar peserta penyuluhan dapat menyerap materi penyuluhan dengan baik, maka masing-masing peserta diberi print out materi penyuluhan. Alat peraga yang digunakan dalam ceramah ini adalah alat penjebak partikel tersuspensi (sedimen trap) yang sudah jadi dan dijelaskan fungsi masing-masing bagiannya. Sedimentasi adalah proses pengendapan materi tersuspensi oleh gravitasi, materi tersuspensi berupa partikel, seperti lempung atau silts, yang berasal dari sumber air dan sisa pelet yang tidak termakan oleh ikan Patin. Materi tersuspensi atau disebut floc terbentuk dalam air dan senyawa kimia. Sedimentasi berlangsung dengan cara memperlambat velocity air yang diberi perlakuan sampai suatu keadaan dimana partikel tidak lagi tersuspensi. Bila velocity tidak lagi mendukung transport partikel, gravitasi akan memisahkannya dari aliran air.

Ukuran dan jenis partikel yang akan dipisahkan memiliki pengaruh yang nyata terhadap operasional kolam sedimentasi, karena berat jenisnya, pasir atau silt dapat dipisahkan dengan mudah. Velocity air dapat diperlambat sampai dengan kurang dari $60 \mathrm{~cm} /$ detik, dan sebagian besar gravel dan grit dapat dipisahkan karena gravitasi. Sebaliknya, materi yang bersifat koloid, tidak akan mengendap sampai materi itu terkoagulasi dan terflukulasi melalui penambahan bahan kimia, seperti garam besi atau alumunium sulfat. Bentuk partikel juga mempengaruhi karakteristik pengendapan. Partikel yang berbentuk bulat lebih mudah diemdapkan daripada partikel yang bentuknya tidak beraturan. Setiap partikel cenderung 
memiliki sedikit muatan elektrik. Partikel dengan muatan yang sama cenderung saling menolak. Hal ini membuatnya tidak bergabung membentuk flok tapi mengendap. Alat yang digunakan untuk menangkap partikel terlihat pada Gambar 1 dan dipasang secara vertical di dasar (5 cm dari dasar kolam) untuk partikel yang menuju ke dasar.

Kolam ikan terdiri dari beberapa zona, yaitu: (1) Zona Inlet, harus tidak mengganggu aliran dalam kolam; (2) Zona Pengendapan, Zona ini zona terluas dalam kolam yang memberikan peluang pada partikel tersuspensi untuk mengendap; (3) Zona slude, terletak di bawah kolam dan merupakan penyimpanan sludge sementara sebelum dibuang ke tempat pembuangan; dan (4) Zona Outlet, harus membuat aliran air yang tenang dan mengontrol kedalaman kolam.

\section{Perangkaian Alat Sedimen Trab}

Alat sedimen trap dibuat dari plat besi tahan karat dan ditanam di dasar kolam. Alat ini dilengkapi dengan botol sampel dan ditarik dengan tali (Gambar 1). Lama pengambilan sampel partikel yang terjebak di botol dapat 24 jam atau 1 hari, 2 hari, 3 hari dan paling lama 1 minggu ( 7 hari). Pengukuran sampel air yang mengandung partikel tersuspensi ini dilakukan secara insitu dan langsung dengan menuangkan air sampel yang ada di botol ke tabung in off (berbentuk kerucut dan memiliki skala) serta diukur dengan satuan $\mathrm{ml} / \mathrm{L}$.

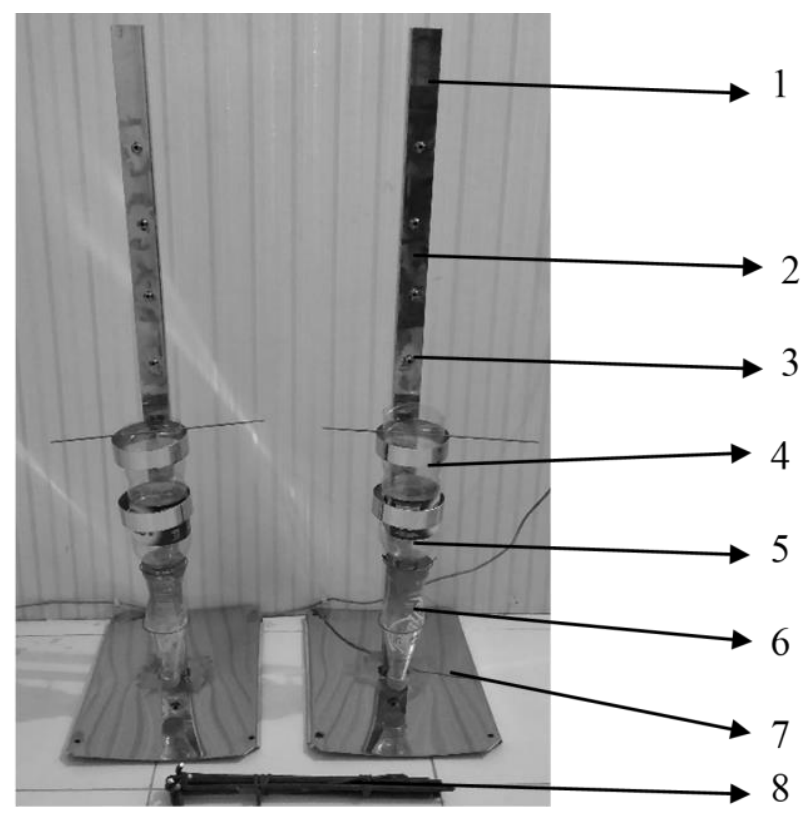

Gambar 1. Dua unit alat sedimen trap untuk mengukur laju sedimentasi

Keterangan gambar:

1. Stik penyangga yang dilengkapi lubang ditengah dengan jarak antar lubang $5 \mathrm{~cm}$.

2. Lubang pada stik digunakan untuk menggantung botol sampel/penjerap partikel.

3. Stik besi penggantung ring

4. Ring penyangga botol sampel

5. Botol sampel atas sebagai pengarah partikel

6. Botol sampel bawah sebagai pengumpul partikel

7. Plat besi dasar pemisah sedimen dengan air kolam dan dilengkapi dengan 4 lubang pada susutsudutnya

8. Empat (4) buah stik besi untuk ditancapkan ke dasar kolam

Adapun cara perangkaian alat sedimen trap adalah: (a) Pasang botol penampung atas dan bawah pada stik penyangga pada lubang nomor 1 dari bawah (kedalaman $5 \mathrm{~cm}$ dari dasar kolam) dengan bantuan tali dan disangga oleh kawat untuk memudahkan dalam pengambilan sampel; (b) Pada bagian bawah botol diberi pemberat agar posisi botol tetap tegak lurus; (c) Alat dimasukkan ke dalam kolam hingga menyentuh dasar; (d) Setiap sudut alat di tancapkan 
besi agar alat tidak tumbang atau berpindah posisi; dan (e) Untuk pengambilan sampel, tarik terlebih dahulu botol paling atas dan diikuti kemudia botol yang berisi sampel partikel tersuspensi.

\section{Diskusi dan Evaluasi}

Pada sesi ini peserta diberi kesempatan untuk bertanya kepada penyuluh dan kemudian penyuluh akan menjelaskan/ menjawab pertanyaan tersebut. Kemudian penyuluh akan memberi pertanyaan kepada peserta untuk mengevaluasi daya serap mereka terhadap materi penyuluhan. Selain itu sikap antusiasme peserta selama jalannya penyuluhan dievaluasi dengan kriteria seperti pada Tabel 1.

Tabel 1. Kriteria antusiasme dan sikap peserta selama mengikuti penyuluhan

\begin{tabular}{|c|c|c|}
\hline Antusiasme Peserta & Skor & Keterangan \\
\hline Sangat rendah & $1,0-1,49$ & $\begin{array}{l}\text { Menunjukkan sikap ogah-ogahan dan } \\
\text { meninggalkan ruangan sebelum acara selesai }\end{array}$ \\
\hline Rendah & $1,5-1,99$ & $\begin{array}{l}\text { Menunjukkan sikap masa bodoh dan } \\
\text { tidakmemperhatikan materi yang disampaikan, } \\
\text { tetapi tetap berada di ruangan selama acara } \\
\text { berlangsung }\end{array}$ \\
\hline Sedang & $2,0-2,49$ & $\begin{array}{l}\text { Kadang-kadang memperhatikan, tetapi } \\
\text { kadang-kadang melakukan hal lain seperti } \\
\text { asyik menggunakan HP }\end{array}$ \\
\hline Tinggi & $2,5-2,99$ & $\begin{array}{l}\text { Menyimak dengan baik, tetapi pasif, tidak aktif } \\
\text { dalam diskusi }\end{array}$ \\
\hline Sangat tinggi & $3,0-3,49$ & $\begin{array}{l}\text { Menyimak dengan baik dan aktif dalam } \\
\text { diskusi }\end{array}$ \\
\hline
\end{tabular}

\section{HASIL DAN KETERCAPAIAN SASARAN}

Secara geografis Desa Koto Masjid terletak di wilayah Kecamatan XIII Koto Kampar,Kabupaten Kampar provinsi Riau yang berbatas dengan: sebelah utara dengan Desa Batu Langka, Kecamatan Bangkinang Barat; sebelah timur dengan Desa Silam, Kecamatan Bangkinang Barat; sebelah selatan dengan Merangin, Kecamatan Bangkinang Barat; dan sebelah barat dengan Desa Pulau Gadang, Kecamatan XIII Koto Kampar.

Luas wilayah Desa Koto Masjid adalah 425,5 ha. Berupa daratan yang bertopografi perbukitan. Daratan dimanfaatkan sebagai lahan perikanan (kolam darat) dengan jumlah 357 petani ikan air tawar. Desa Koto Mesjid dikenal sebagai Kampung Patin dengan motto "Tiada Rumah Tanpa Kolam Ikan" karena dengan adanya budidaya ikan patin. Lebih dari 700 kolam dengan luas 50 ha dan sedikitnya menghasilkan sebanyak 12 ton ikan patin perharinya.

Iklim desa Koto Masjid, sebagaimana desa-desa lain yang ada di Indonesia mempunyai iklim kemarau dan penghujan, hal tersebut mempunyai pengaruhlangsung terhadap usaha perikanan yang ada di Desa Koto Masjid, KecamatanXIII Koto Kampar. Kondisi lingkungan Desa Koto Masjid merupakan wilayah yang berada dipingiran waduk PLTA Koto Panjang. Hal ini menjadikan Desa Koto Masjid, selain sebagai pusat pengembangan perikanan kolam darat, juga berpotensi dalampengembangan keramba jaring apung (KJA) di waduk PLTA Koto Panjang. Perkembangan bidang perikanan Koto Masjid juga tidak terlepas dari dukungan sumber air yang sangat memadai. Secara administratif Desa Koto Mesjid termasuk dalam Wilayah Kecamatan XIII Koto Kampar Kabupaten Kampar Provinsi Riau dan merupakan Desa yang dibina lansung oleh PT. TELKOM Indonesia dan Pemerintah Kabupaten Kampar, sehingga mendapat julukan sebagai Kampung Patin. 


\section{Kegiatan Pengabdian}

Kegiatan pengabdian ini diawali dengan pertemuan yang diadakan di gedung sebaguna kantor desa. Dalam pertemuan tersebut para metani ikan Patin diberi 10 pertanyaan yang mengungkap kemampuan dasar mereka tentang perawatan kolam dan dikaitkan dengan laju pendangkalan kolam akibat tingginya partikel tersuspen (laju sedimentasi) serta hubungannya denga kualitas ikan yang dipanen (Gambar 2).

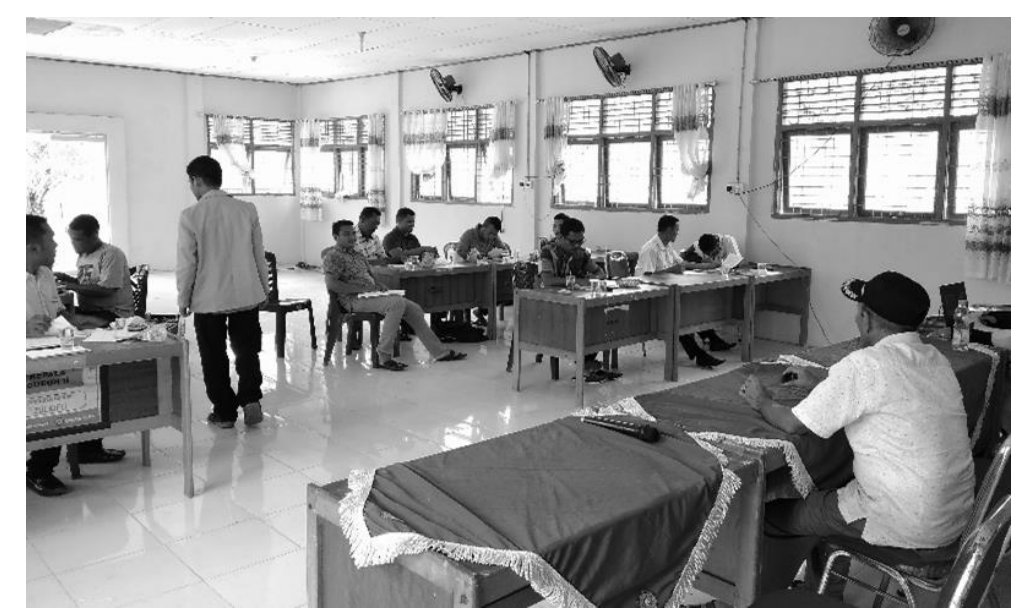

Gambar 2. Kegiatan test awal tentang perawatan kolam dan dikaitkan dengan laju pendangkalan kolam akibat tingginya partikel tersuspen oleh petani ikan Patin.

Setelah didapat data kemampuan dasar para petani ikan dilanjutkan dengan penyampaian materi dengan metoda ceramah tentang Teknik Laju Sedimentasi Pada Kolam Tanah PMK Budidaya Ikan Patin Intensif dan diskusi secara aktif. Pengenalan dan demostrasi alat perangkap padatan tersuspensi yang ditanam di kolam ikan Patin juga dijelaskan dengan memperlihatkan alat yang sudah jadi dan pemutaran video saat alat dipasang di kolam percontohan ikan Patin yang dibudidayakan secara intensif (Gambar 3).

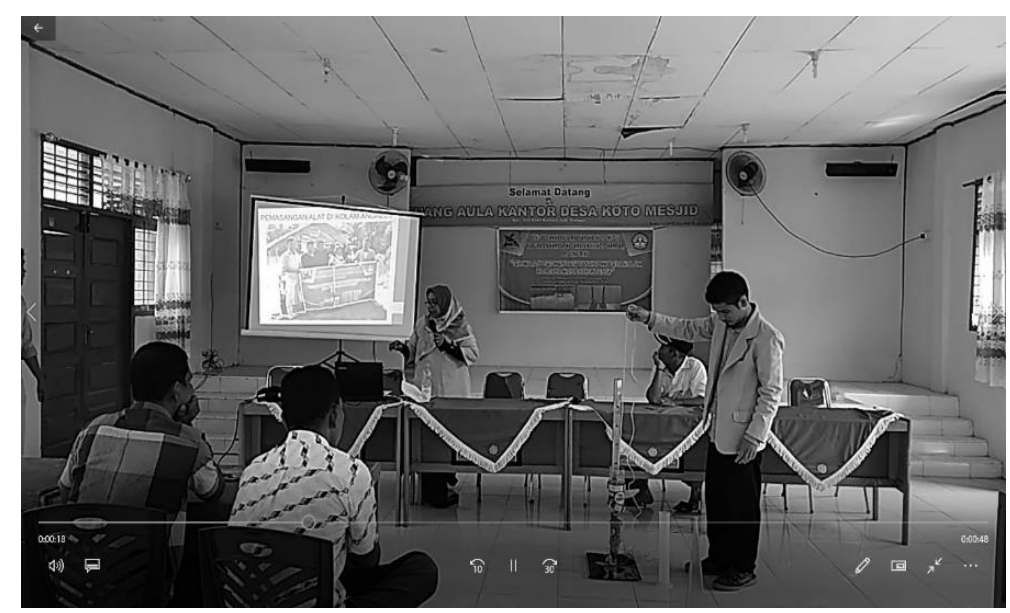

Gambar 3. Pemutaran video demostrasi alat perangkap padatan tersuspensi yang ditanam di kolam ikan Patin. 


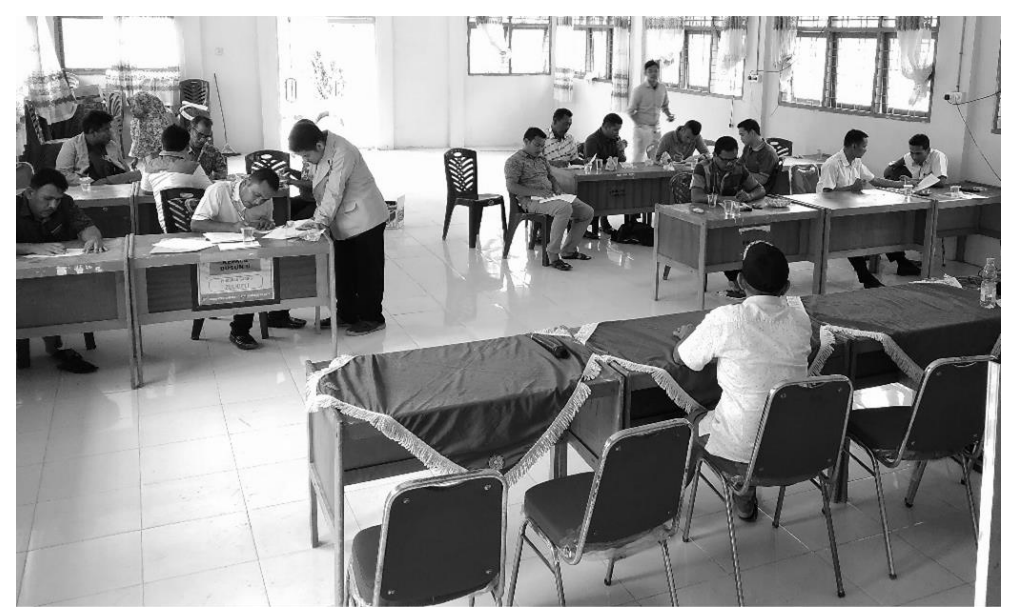

Hasibuan et

al.

Gambar 4. Kegiatan test akhir tentang perawatan kolam dan dikatkan dengan laju pendangkalan kolam akibat tingginya partikel tersuspen oleh petani ikan Patin.

Pada akhir kegiatan dilakukan test kembali tentang pengetahuan para petani ikan. Hasil dua test yang dilakukan (awal dan akhir) akan menjadi dasar pengolahan data dalam mengetahui respon para petani ikan terhadap materi pengabdian yang diberikan (Gambar 4), dan Gambar 5 foto bersama dengan perwakilan petani ikan Patin (a) serta pemasangan alat di kolam petani ikan Patin intensif (b) dan (c).

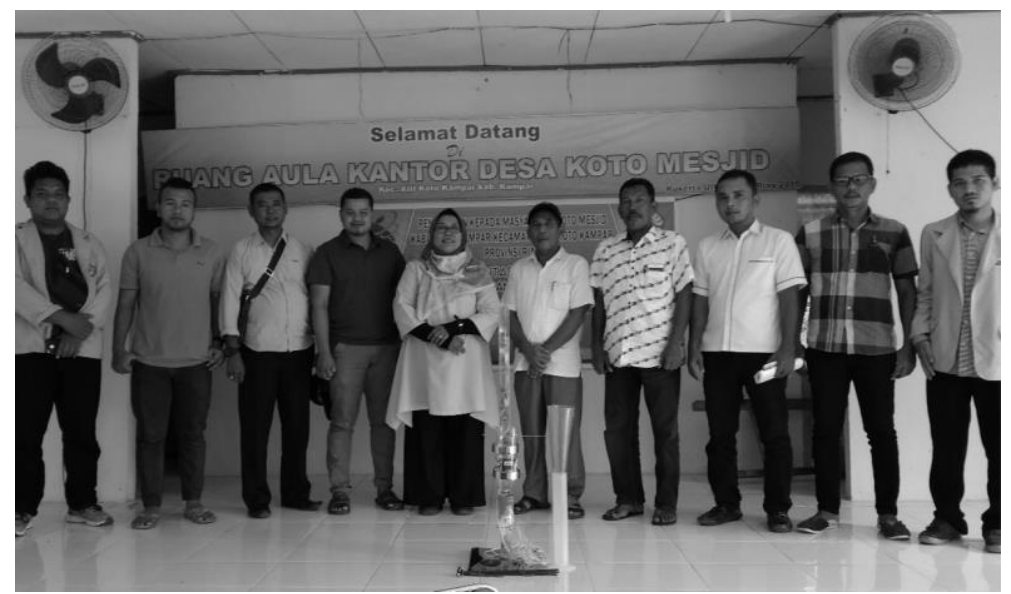

(a)

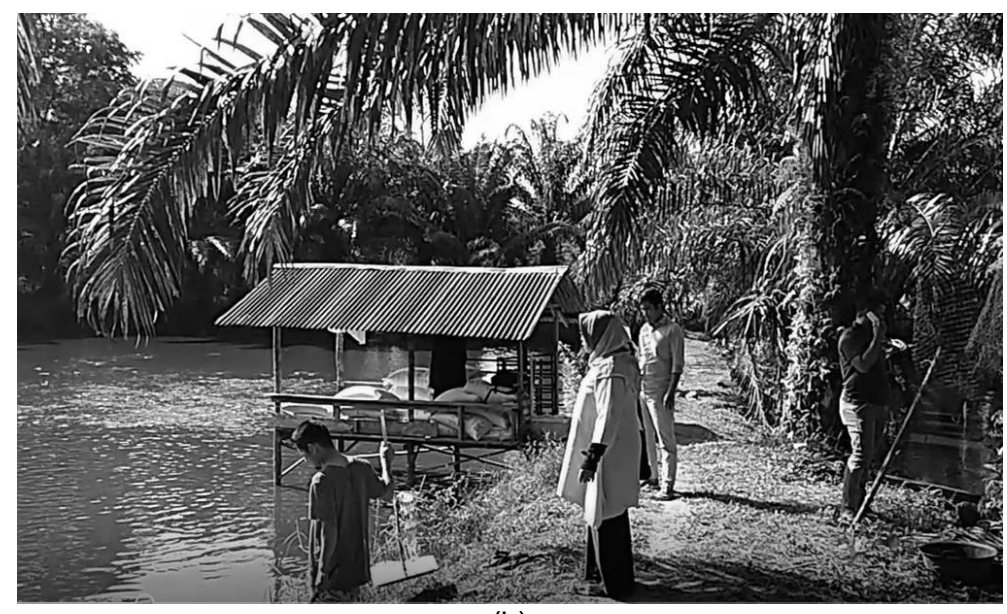

(b) 


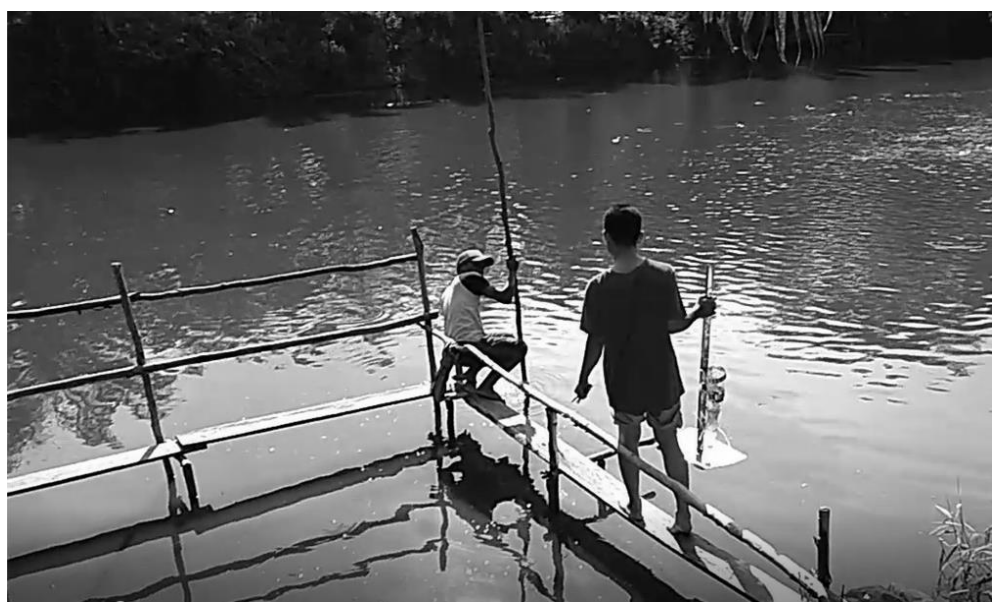

(c)

Gambar 5. Foto bersama dengan perwakilan petani ikan Patin (a) serta pemasangan alat di kolam petani ikan (b, c)

\section{Pengolahan Data Kemampuan Dasar Awal dan Akhir Petani Ikan Patin}

Pengetahuan dasar petani ikan Patin tentang laju sedimentasi pada kolam ikan Patin terdiri dari 10 kategori, yaitu:

1. Pengenalan dasar kolam

2. Cara pengelolaan dasar kolam

3. Sumber lumpur kolam

4. Pengaruh lumpur kolam terhadap produksi ikan

5. Pengurasan lumpur kolam dalam setahun

6. Pemanfaatan lumpur kolam

7. Pengaruh lumpur kolam ke warna air kolam

8. Peningkatan lumpur kolam dengan bau iukan

9. Cara mengetahui lumpur kolam meningkat

10. Alat mengukur volume lumpur kolam

Berdasar data yang dikumpulhan dari test kemampuan dasar awal dan akhir didapat dibuat dalam bentuk grafik garis sebagaimana terlihat pada Gambar 6 .

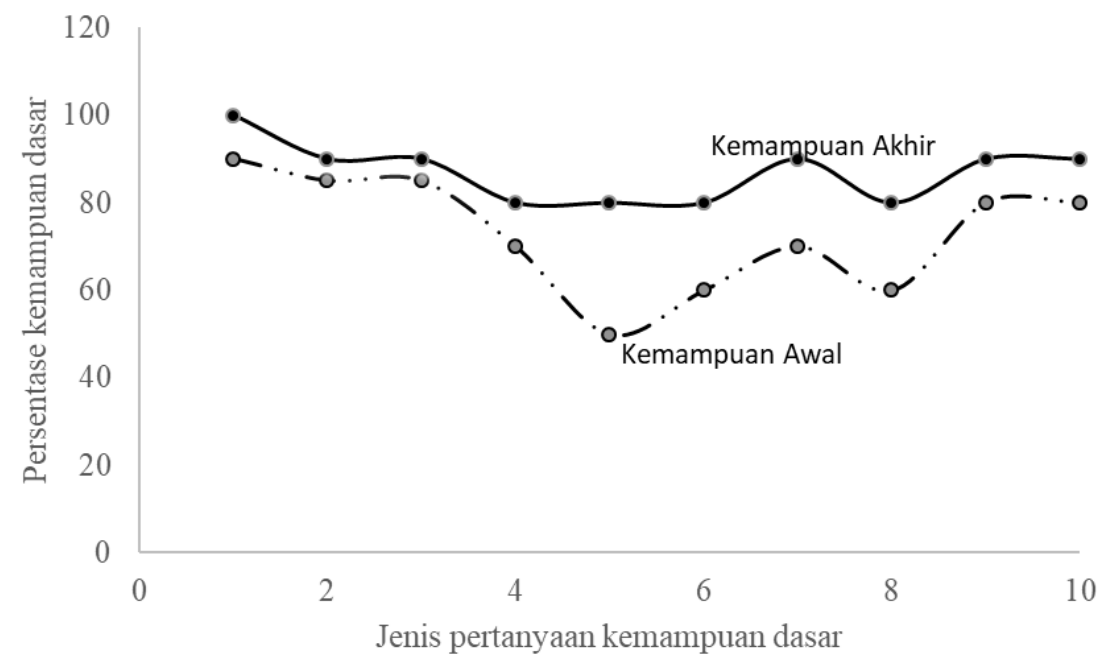

Gambar 6. Hasil test kemampuan dasar (\%) peserta pelatihan petani ikan patin yang diuji pada awal dan akhir kegiatan pengabdian. 
Berdasarkan Gambar 6 terlihat bahwa terjadi peningkatan kemampuan pengetahuan dasar para petani ikan Patin setelah diberi materi penyuluhan laju sedimentasi pada kolam ikan Patin. Kegiatan pengabdian pada masyarakat ini juga mengikutsertakan mahasiswa Kuliah Kerja Nyata yang ada di Desa Koto Masjid. Kemampuan dasar petani ikan sangat menentukan dalam pemahaman mereka tentang padatan tersuspensi yang ada di air kolam dihubungkan dengan warna air kolam coklat kehitaman dan proses pendangkalan kolam (jumlah lumpur dasar kolam), serata rasa ikan Patin pada saat produksi.

\section{Pengukuran Laju Sedimentasi}

Pengolahan data padatan tersuspensi dilakukan setiap hari dan setiap minggu. Data ini dikumpulkan dari beberapa kolam milik petani ikan Patin. Kolam di kelompokkan berdasar umur kolam yaitu < 5 tahun, 6-10 tahun, 11-15 tahun dan 16-20 tahun. Data padatan tersuspensi diperoleh dari alat yang dipasang di kolam. Botol perangkap padatan yang terpasang pada alat berfungsi untuk mengukur padatan tersuspensi di air kolam dan diukur secara manual dengan satuan $\mathrm{ml} / \mathrm{l}$ air kolam, sehingga alat ini disebut juga perangkap padatan tersuspensi. Hasil pengujian digunakan untuk membaca padatan tersuspensi di air kolam yang selanjutnya dapat berkontribusi dalam mempercepat laju sedimentasi/pendangkalan kolam. Dampak kegiatan penyuluhan ini diharapkan semua petani ikan Patin dapat memasang alat ini baik secara mandiri ataupun secara kelompok. Kegiatan penyuluhan ini dimaksudkan untuk memperkenalkan alat perangkap padatan tersuspensi, sehingga petani ikan Patin dapat mengambil keputusan secara cepat untuk mengganti air kolam berdasarkan jumlah padatan tersuspensi ini. Hasil monitoring di lapangan dapat dilihat pada Gambar 7.

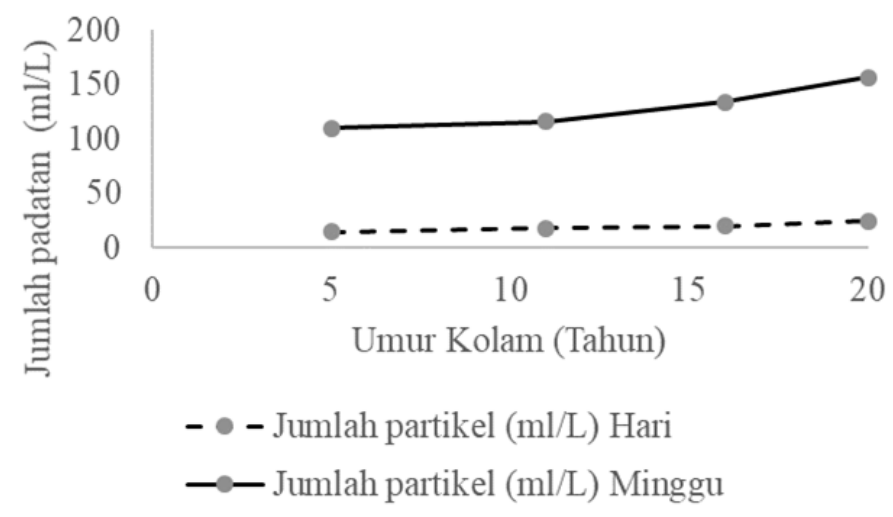

Gambar 7. Jumlah padatan tersuspensi pada berbagai umur kolam ikan Patin

Berdasarkan Gambar 7 terlihat bahwa padatan tersuspensi yang terukur setiap hari dan setiap minggu menunjukkan kenaikan dengan bertambahnya umur kolam. Rata-rata padatan tersuspensi pada semua umur kolam adalah $19,5 \mathrm{ml} / \mathrm{L}$ perhari dan $129,25 \mathrm{ml} / \mathrm{L}$ per minggu. Berdasarkan data ini maka pengelolaan dasar kolam harus dilakukan setiap panen terutama saat pengeringan kolam perlu pengurasan lumpur. Lumpur kolam yang diangkat dari dasar kolam ini dapat dimanfaatkan untuk merapikan tanggul kolam atau sedimen dasar kolam ini dapat dijadikan media tanaman untuk sayuran atau tanaman palawija.

\section{Tingkat Ketercapaian Sasaran Program}

Hasil pengamatan terhadap sikap antusiasme peserta penyuluhan menunjukkan bahwa petani yang menunjukkan antusiasme sedang 4 orang, tinggi 11 orang dan sangat tinggi 10 orang, sebagaimana terlihat pada Tabel 2. Rerata skor antusiasme peserta adalah 4,24 berarti besar dari 3,0, dengan demikian dapat dikatakan peserta yang mengikuti penyuluhan teknik laju sedimentasi pada kolam patin intensif tanah PMK pada kolam budidaya ikan Patin intensif di desa Koto Mesjid Kecamatan XIII Koto Kampar. memiliki antusias sangat tinggi. Hal ini menunjukkan bahwa kebanyakan dari masyarakat tersebut ingin mendapatkan bekal 
pengetahuan dan segera memperaktekkan pengukuran padatan tersuspensi pada kolam masing-masing.

Tabel 2. Hasil Evaluasi Sikap antusiasme Peserta Selama Mengikuti Penyuluhan

\begin{tabular}{cccc}
\hline Antusiasme peserta & Skor & Jumlah & Total skor \\
\hline Sangat rendah & 1 & 0 & 0 \\
Rendah & 2 & 0 & 0 \\
Sedang & 3 & 4 & 12 \\
Tinggi & 4 & 11 & 44 \\
Sangat tinggi & 5 & 10 & 50 \\
\hline & Total & 25 & 106 \\
\hline
\end{tabular}

\section{KESIMPULAN}

Pelatihan pendugaan laju sedimentasi pada kolam tanah budidaya ikan patin intensif di desa Koto Mesjid Kecamatan XIII Koto Kampar telah menghasilkan cara pemantauan kualitas air kolam melalui pengukuran padatan tersuspensi menggunakan alat perangkap padatan tersuspensi. Rata-rata padatan tersuspensi pada semua umur kolam adalah 19,5 ml/L perhari dan 129,25 ml/L per minggu. Pengelolaan dasar kolam harus dilakukan setiap panen terutama saat pengeringan kolam perlu pengurasan lumpur. Petani ikan Patin memiliki antusias sangat tinggi untuk mempraktekkan alat pada kolam masing-masing. Adanya penyuluhan ini sangat bermanfaat dalam memberikan bekal ilmu pengetahuan sehingga masyarakat yang berprofesi sebagai petani ikan Patin dapat mengatur waktu penggantian air kolam dengan mudah.

\section{UCAPAN TERIMA KASIH}

Penulis mengucapkan terimakasih kepada Lembaga Penelitian dan Pengabdian kepada Masyarakat Universitas Riau skema hibah Pengabdian kepada Masyarakat tahun anggaran 2018 yang telah mendanai dalam pelaksanaan kegiatan pengabdian dengan nomor kontrak 1292/UN.19.5.1.3/PP/2018 dan seluruh Mahasiswa KKN Universitas Riau tahun 2018 di Desa Koto Mesjid Kecamatan XIII Koto Kampar, Provinsi Riau.

\section{Daftar Pustaka}

1. Hasibuan, S. 2011. Rekayasa Tanah Dasar Kolam Inceptisol Melalui Penambahan Ultisol Dan Vertisol Untuk Meningkatkan Pertumbuhan Alga Dasar Pakan Larva Nila Merah (Oreochromis sp.). Disertasi program doktor. Ilmu Tanah, Fakultas Pertanian, Universitas Gadjah Mada.

2. Hasibuan, S. 2012. Produktivitas kolam pembesaran larva nila merah dengan tanah dasar Inceptisol yang dimarel bahan Ultisol dan Vertisol. Jurnal Perikanan dan Kelautan 17(2): 11-27.

3. Hasibuan, S., B. D. Kertonegoro, K. H. Nitimulyo, \& E. Hanudin. 2011. Manipulation of Inceptisols Pond Bottom Soil Through Addition of Ultisols and Vertisols for Rearing of Red Tilapia (Oreochromis sp.) Larvae. Indonesian Aquaculture Journal 6(1): 59-70. https://doi.org/10.15578/iaj.6.1.2011.59-70

4. Sonnenholzner, S., \& C. E. Boyd. 2000. Vertical gradients of organic matter concentration and respiration rate in pond bottom soils. Journal of The World Aquaculture Society 31: 376-380. https://doi.org/10.1111/j.1749-7345.2000.tb00887.x 